Int. J. Speleol. 19 (1990): 29-38

\title{
Laboratory studies of predatory behaviour in two subspecies of the Carabid cave beetle: Neaphaenops tellkampfi
}

\author{
David M. Griffith *
}

\begin{abstract}
SUMMARY
Comparative studies on the foraging behavior of Neaphaenops tellkampfi tellkampfi and $N$. t. meridionalis demonstrated adaptation to different environments. The southern subspecies $N$. t. meridionalis, which is found in wet muddy caves where cave cricket eggs are unlikely prey, did not locate buried cricket eggs and dug fewer and less accurate holes in the lab than the nominate subspecies. $N$. t. tellkampfi, which reaches high densities in sandy deep cave environments where cricket eggs are the only viable prey, gained significantly greater weight than meridionalis when presented buried cricket eggs as prey. There was no difference with respect to weight change between the subspecies in the presence of Ptomaphagus larvae. N. t. meridionalis gained weight at a significantly greater rate than the nominate subspecies with enchytraeid worms as prey. Enchytraeid worms represent the natural prey most likely to be encountered by N. t. meridonalis. $25 \%$ of beetle holes were dug deep enough to potentially located buried cricket eggs. Since Hubbell and Nortons' morphological data on the relationship between cricket ovipositor lenghth and beetle predation have some problems with sample sizes and minor assumptions, I conclude that there are no unequivocal data that support the possibility of coevolution between Neaphaenops and Hadenoecus.
\end{abstract}

\section{INTRODUCTION}

Comparative studies of behavioral adaptation are common in the literature (e.g., Blumer, 1979; Greenwood, 1980; Gross and Sargent, 1985; Wittenberger and Tilson, 1980). The pattern of adaptation to the environment revealed in these studies is compelling (see Dobsen, 1985, for an alternative viewpoint). In this paper I present evidence of adaptation based on laboratory studies on foraging behavior of two

* Department of Biological Sciences (M/C) 066, University of Illinois at Chicago, Box 4348 Chicago, Illinois 60680 U.S.A. 
subspecies of carabid cave beetles, Neaphaenops tellkampfi tellkampfi (Erichson, 1844) and N.t. meridionalis Barr, 1959.

The two subspecies are appropriate for comparative studies because 1) taxonomic work by Barr (1979) provides hypotheses which may be tested by behavioral studies, and 2) electrophoretic work by Kane and Brunner (1986) has supported many of Barr's taxonomic conclusions based on morphological characters. Barr also made evolutionary speculations on the origin of predatory specialization of Neaphaenops on the eggs of the cave cricket Hadenoecus subterraneus (Orthoptera: Rhaphidophoridae). These evolutionary statements are considered in this paper.

The purpose of this paper is to (1) present and interpret the results of a laboratory study on the foraging behavior of two subspecies of Neaphaenops on different potential prey items, and 2) to present new data on and to re-evaluate the hypothesis proposed by Hubbell and Norton (1978) of coevolution between Neaphaenops and the cave cricket Hadenoecus subterraneus. This hypothesis suggests that beetle predation on cricket eggs has led to the evolution of longer ovipositors of cave crickets. Longer ovipositors may make it harder for beetles to locate buried cricket eggs by virtue of placing them deeper in the substrate.

The carabid cave beetle N.t. tellkampfi is commonly found in deep cave sandy sites, where it locates and consumes the eggs of the cave cricket Hadenoecus subterraneus (Orthoptera: Rhaphidophoridae). The success of nominate tellkampfi at locating cricket eggs, a high energy resource, accounts for the relatively high densities of beetles observed in sandy sites (Norton et al., 1975; Kane and Poulson, 1976; Barr and Kuehne, 1971).

The southern subspecies N.t. meridionalis occurs in caves that are typically wet and muddy, flood regularly, and in which sandy substrates with cricket eggs are largely absent. The feeding habits of meridionalis in the cave are generally unknown. Barr (1979) reports a single observation in which a beetle was observed "eating a small chrysomelid beetle that had washed into the cave through an upper sinkhole entrance". On one occasion I observed a beetle eating the carcass of a cave cricket. Other potential prey items of $>1 \mathrm{mg}$ that co-occur with both subspecies include the larvae of the Leiodid beetle Ptomaphagus hirtus and enchytraeid worms.

\section{METHODS AND MATERIALS}

The nominate tellkampfi subspecies was collected from Edwards Avenue in Great Onyx Cave in Mammoth Cave National Park. Edwards Avenue is a sandy deep cave site in which the eggs of the cave cricket represent virtually the only prey item for the beetles (Kane et al., 1975; Norton et al., 1975; Kane and Poulson, 1976).

The southern subspecies, $N$. t. meridionalis, was collected from Hoy 
Cave in Simpson County, Kentucky, for return to the lab for comparative behavioral studies with nominate tellkampfi. Hoy Cave is located 45 miles southwest of Mammoth Cave National Park. Hoy Cave is a wet muddy cave that floods regularly. Cave crickets are present, but since sand is not available for ovipositing, it is not known where the crickets lay their eggs.

Three separate experiments used subspecies as treatments, and compared weight change in the presence of three potential food items. The food items for the experiments were (1) cricket eggs, (2) larvae of the Leiodid beetle Ptomaphagus hirtus, and (3) enchytraeid worms. The eggs were collected by sifting sand in Great Onyx Cave within beetle-free enclosures. Ptomaphagus larvae were raised in lab cultures from wild caught animals (see Peck, 1975, for lab culture procedures). Enchytraeid worms were purchaesed from Carolina Biological Supply Company because it was impossible to extract them intact from the mud/clay/silt substrates in the cave. In addition to the above experiments, I ran two separate assays of weight change on sand without food.

There were tive replicates per treatment for all treatments, and the interspersion of all treatments was randomized within an environmental chamber. There was one beetle per bowl. All experiments were run for 15 days at a temperature of $15^{\circ} \mathrm{C}$ within $21 \mathrm{~cm}$ diameter glass finger bowls. The tops of the bowls were covered with plastic to maintain high humidities. Beetles were anesthetized with $\mathrm{CO}_{2}$ and weighed to the nearest $10^{-3} \mathrm{mg}$ with a Cahn 25 electrobalance at the beginning of each experiment, and at 2-3 day intervals during the course of each experiment. The main response variable was per cent weight change per day per beetle. The number and spatial distribution of holes dug in the egg finding experiment were also recorded, since holes dug in sand represent foraging efforts of beetles that are trying to locate cricket eggs (Kane and Poulson, 1976).

I used a t-test for analyses of weight change data. Log likelihood ratio tests (G-tests) were used to test null hypotheses of no difference in numbers of holes dug between treatments and in simulated mounds vs. not in simulated mounds within a treatment (Sokal and Rohlf, 1981).

\section{Egg finding experiment}

In the egg finding experiment, four cricket eggs were buried under simulated cricket oviposition mounds in each bowl. The bowls were half-filled with sand collected in Great Onyx Cave. The necessity of cricket oviposition mounds for cave beetles to locate cricket eggs was established in prior studies (Griffith, 1990).

\section{Ptomaphagus larvae experiment}

In the Ptomaphagus larvae finding experiment, four piles $(1 \mathrm{~cm}$ diameter) of yeast (food for the larvae) were placed in each bowl. The bowls were half-filled with mud collected from Hoy Cave. Two large 
(prepupal), two medium (2nd instar), and two small (1st instar) larvae were released in each bowl.

Enchytraeid worm experiment

For the Enchytraeid worm experiment, four small $(1 \mathrm{~cm}$ diameter) piles of dirt from the worm culture medium were placed in each bowl. All bowls were half-filled with mud collected from Hoy Cave. Two large $(>2 \mathrm{~cm})$, two medium $(1.0-2.0 \mathrm{~cm})$, and two small $(<1 \mathrm{~cm})$ worms were released in each bowl.

Cricket ovipositor lenghts and beetle hole depths

Adult crickets were captured by hand in Great Onyx Cave and were brought back to the lab to measure ovipositor length. Five female crickets were removed on ten separate dates over the course of one year for a total of 50 crickets.

Beetle hole depths for the nominate subspecies were measured in the lab. Although the experiment was originally designed to determine how beetles located buried cricket eggs (see Griffith, 1990, for details) here only the frequency distribution of hole depths $(\mathrm{N}=97)$ is given for comparison with cricket ovipositor lengths.

\section{RESULTS}

The results of the two separate assays for weight change on sand without food suggest that there is no difference between the two subspecies, but there are clear subspecific differences in ability to find and consume prey items (Figure 1).

\section{Egg finding experiment}

Nominate tellkampfi gained significantly more weight than meridionalis $(\mathrm{t}=3.509, \mathrm{p}<.02)$, but only two out of five nominate tellkampfi actually ate eggs and gained weight. All five meridionalis beetles lost weight. $N$. $t$. meridionalis was unable to locate cricket eggs due to poorer accuracy of hole digging (only 3 holes in mounds vs. 23 holes in mounds for nominate tellkampfi, $\mathrm{G}_{\mathrm{adj}}=17.122, \mathrm{p}<.001$ ) and fewer holes ( 13 holes were dug by N.t. meridionalis vs. 47 holes for nominate tellkampfi, $\left.\mathrm{G}_{\mathrm{adj}}=10.144, \mathrm{p}<0.005\right)$.

\section{Ptomaphagus larvae experiment}

There was no difference in weight change between the two subspecies when given Ptomaphagus larvae as prey $(t=-0.089, p>9)$. Only two beetles (one of each subspecies) gained weigth. All six larvae disappeared from these two bowls. There was no difference between the treatments in the total number of larvae consumed, with 13 larvae disappearing in the nominate tellkampfi treatment and 14 larvae disappearing in the meridionalis treatment. At least one larva disappea- 


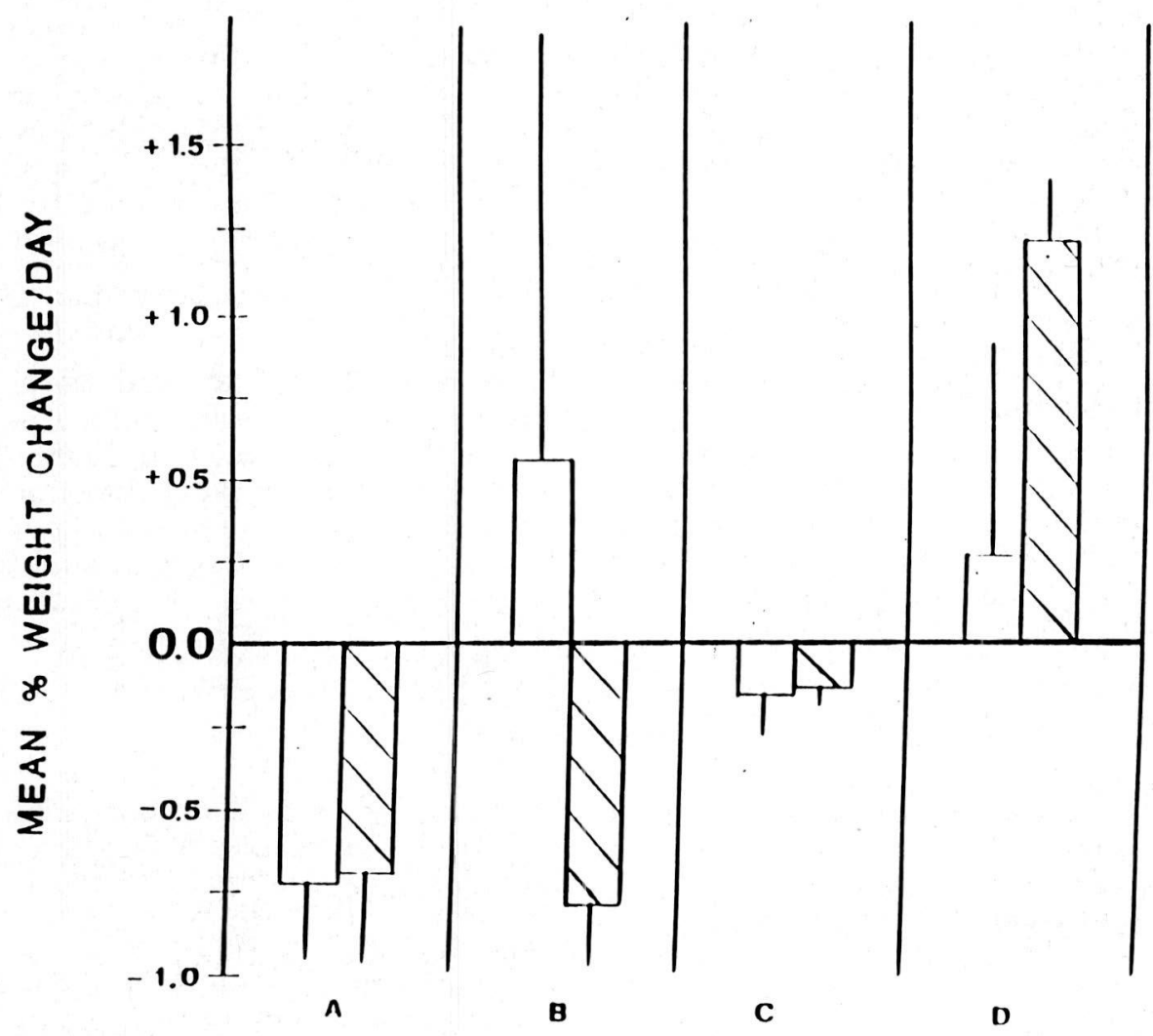

Fig. 1 - The mean per cent weight changes per day for the three feeding experiments and the two separate assays without food show that: 1) There is little difference between the subspecies when food is absent (A). 2) N.t. meridionalis lost more weight than $N$. $t$. tellkampfi when given buried cricket eggs (B). 3) Both subspecies lost weight in the presence of Ptomaphagus larvae (C). 4) N. t. meridionalis gained significantlv more weight than nominate tellkampfi when given enchytraeid worms (D). Vertical lines indicate standard deviations. Open bars represent $N$. t. tellkampfi and hatched bars represent $N$. $t$. meridionalis. 
red from each bowl. I did not directly observe predation in this experiment.

\section{Enchytraeid worm experiment}

N. t. meridionalis gained weight at a significantly greater rate than nominate tellkampfi when presented Enchytraeid worms $(\mathrm{t}=-3.687, \mathrm{p}$ $<0.02$ ). All beetles of both subspecies gained some weight. Observations of beetles during the course of the experiment revealed contrasting predatory behavior. $N$. $t$. meridionalis used its mandibles to cut up the large enchytraeid worm into several pieces, which it then ate "at leisure". No worms were observed to successfully escape an attack by meridionalis. Nominate tellkampfi, on the other hand, grabbed one of the ends of a large worm, and was usually tossed back and forth as the worm struggled to free itself. The worm was successful at freeing itself from nominate tellkampfi on 5 out of 12 occasions.

\section{Cricket ovipositor lengths and beetle hole depths}

The frequency distribution of cricket ovipositor lengths and beetle hole depths is presented in Figure 2. The mean depth of beetle holes was $11 \mathrm{~mm}$. Mean cricket ovipositor length was $13.5 \mathrm{~mm}$. Notice the higher variance in beetle hole depths when compared to the cricket ovipositor lenghts. Since cricket eggs are $2 \mathrm{~mm}$ in length, a beetle needs to dig only' $11.5 \mathrm{~mm}$ deep before reaching the top of an egg. Approximately $25 \%$ of beetle hole depths were dug deep enough to potential reach the top of buried cricket eggs.

\section{DISCUSSION}

Barr (1979) believed that the greater degree of morphological departure of meridionalis from the other three subspecies of Neaphaenops indicates that meridionalis is the oldest isolate. Barr also argued that Neaphaenops shares a common ancestry with a group of carabid cave beetles in the genus Pseudanophthalmus that is confined to the southern portion of the range of Neaphaenops. Finally, biogeographic evidence indicates that Neaphaenops appears to be in the process of expanding its range northward. These three lines of evidence led Barr to postulate a southern origin tor Neaphaenops in the vicinity of the meridionalis subspecies. Kane and Brunner (1986), after analyzing electrophoretic data on all four subspecies, agreed with Barr's hypothesis of a southern origin for Neaphaenops.

\section{Specialist or generalist?}

Barr (1979) and Kane and Ryan (1983) suggest that Neaphaenops can eat prey items other than cricket eggs due to evolution of some generalist foraging tendencies that allowed an expansion of the niche to include unfavorable habitats (i.e., habitats where cricket eggs are not 


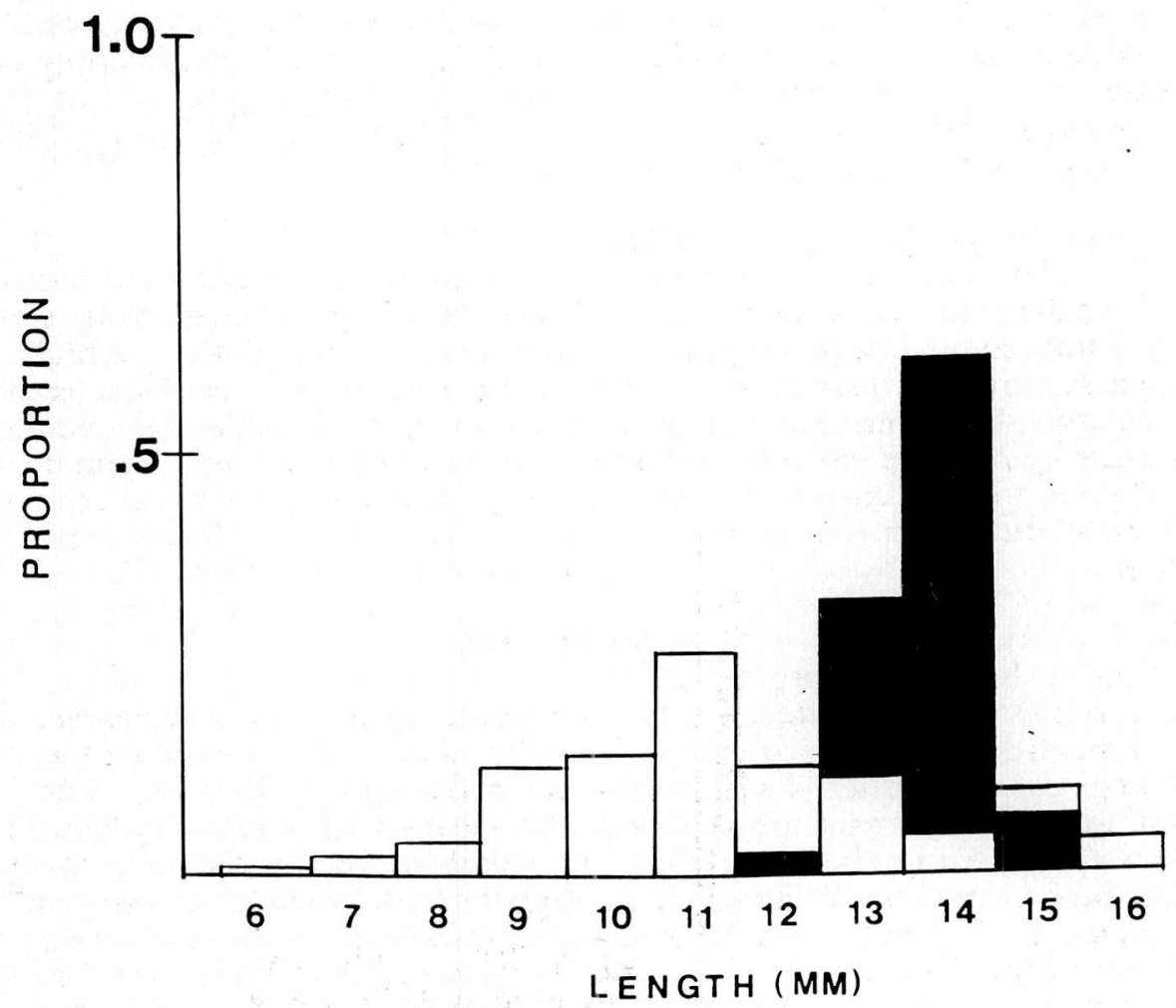

Fig. 2 - The proportional distribution of beetle hole depths (open bars) is relatively flatter than the proportional distribution of cricket ovipositor lengths (solid bars). $\mathrm{N}=97$ for holes; $\mathrm{N}=50$ for cricket ovipositors. 
available). My data show that $N$. $t$. meridionalis could not find cricket eggs in the sand in the lab, and may be more of an enchytraeid worm specialist than a cricket egg specialist. If $N$. $t$. meridionalis has close affinities with the ancestral state, as Barr (1979) suggests, then these results are consistent with Barr's hypothesis that the ancestor of Neaphaenops may have been originally a generalist predator which expanded its range as it evolved cricket egg finding behavior after encountering northern sandy caves. The sequence of events leading to cricket egg specialization can be answered only by further studies on related carabid cave beetles in the genus Pseudanophthalmus. Clearly, the ability of nominate tellkampfi to locate cricket eggs accounts for the high densities measured within sandy sites in its range, and the ability of $N$. t. meridionalis to consume enchytraeid worms, which are most likely prey encountered in wet, muddy caves, is adaptive in the southern part of the species' range.

\section{Coevolution}

Coevolution may be defined as the reciprocal genetic responses of two species to each other over evolutionary time. Studies which demonstrate coevolution between two species in this strict sense are rare (see Futuyma and Slatkin, 1983, for a review). Most of these examples of coevolution involve mutualistic or parasitic relationships (e.g., Feinsinger, 1983; Holmes, 1983).

Hubbell and Norton (1978) hypothesized that the HadenoecusNeaphaenops interaction may be an example of a coevolved predatorprey pair. They compared ovipositor lengths of cave crickets from caves with beetle predators with ovipositor lengths of crickets from caves without beetle predators and determined that cricket ovipositor lengths were significantly longer in cricket populations experiencing beetle predation. The implication was that because of the 1-2 $\mathrm{mm}$ longer ovipositors, eggs were buried 1-2 $\mathrm{mm}$ deeper in the sand, which made it more difficult for beetles to find the eggs. At present, there are no experimental data which directly confirm or reject this connection between ovipositor lengths and beetle predatory success. My data on ovipositor lengths and beetle hole depths show that if ovipositor length were $2 \mathrm{~mm}$ deeper, few beetle holes (approximately $4 \%$, which is a six fold reduction from the original $25 \%$ ) would still be deep enough to locate the eggs. Hubbell and Norton also cited the extensive geographical overlap in the distributions of the two species in support of the coevolutionary hypothesis.

Although the indirect evidence of ovipositor length is strong, there are two principal arguments which may be raised against a coevolutionary hypothesis. First, although cave beetles have evolved specialized behavior to locate buried cricket eggs, cave crickets face many different predators during their life cycle. For example, at cave entrances cave crickets may be consumed by salamanders, wolf spiders, and mice. 
Studies of coevolution show that when one species interacts with many different species, tight coevolutionary relationships among pairs of species are rarely seen (Futuyma and Slatkin, 1983).

Second, Hubbell and Norton may have been wrong in assuming that predation on cricket eggs occurs in all areas where beetles and crickets co-occur. Hubbell and Norton assumed that cricket populations in caves which contain $N$. t. meridionalis experience beetle predation. My experiments show that in the lab meridionalis did not locate buried cricket eggs in the sand. Hubbell and Norton also assume that two other subspecies $(N$. $t$. viator and $N$. $t$. henroti), whose behaviors and ecologies are presently unknown, also eat cricket eggs. When I compare ovipositor lengths of crickets that only co-occur with nominate tellkampfi populations, their data show means of $12.72 \mathrm{~mm}$. ( $\mathrm{N}=11$ caves) and $11.64 \mathrm{~mm}$ ( $\mathrm{N}=14$ caves) for "predated" and "nonpredated" populations, respectively. Although some of the sample sizes within caves were small ( $<5$ individuals), this difference is consistent with a coevolutionary hypothesis.

In conclusion, the data on ovipositor lenghts and beetle hole depths support a hypothesis of coevolution, but further studies are necessary on demographic and morphological traits of Hadenoecus in relation to the presence and absence of beetle predation. These studies are necessary before any definitive statements on coevolution may be made.

\section{AKNOWLEDGEMENTS}

I thank Thomas Poulson, Joel Brown, Robert Willey, James Jones, and Thomas Kane for helpful comments on the manuscript. This work was partially funded by grants from the Cave Research Foundation and the National Speleological Society. I thank the National Park Service for providing access to the caves. This paper is part of a dissertation submitted to the University of Illinois at Chicago in partial fulfillment of the requirements for the degree of Doctor of Philosophy.

\section{LITERATURE CITED}

BARR, T.C. 1979. The taxonomy, distribution, and affinities of Neaphaenops, with notes on associated species of Pseudanophthalmus (Coleoptera, Carabidae). American Museum Novitates, no. 2682.

BARR, T.C. and R. KUEHNE. 1971. Ecological studies in the Mammoth Cave ecosystems of Kentucky. II. the ecosystem. Annales de Speleologie 26: 47-96.

BLUMER, L. 1979. Male parental care in the bony fishes. Quarterly Review of Biology 54: 149-161.

DOBSEN, F. 1985. The use of phylogeny in behavior and ecology. Evolution 39: 1384-1388.

FEINSINGER, P. 1983. Coevolution and pollination, p. 280-310. In D. Futuyma and M. Slatkin (eds.), Coevolution. Sinauęr, Sunderland, MA.

FUTUYMA, D. and M. SLATKIN. 1983. Coevolution. Sinauer, Sunderland, MA.

GREENWOOD, P. 1980. Mating systems, philopatry and dispersal in birds and mammals. Animal Behavior 28: 1140-1162.

GRIFFITH, D. 1990. Ecology and evolution of predatory behavior in the carabid cave beetle Neaphaenops tellkampfi. Ph. D. thesis. University of Illinois at Chicago, Illinois. 
GROSS, M. and R. SARGENT. 1985. The evolution of male and female parental care in fishes. American Zoologist 25: 807-833.

HOLMES, J. 1983. Evolutionary relationships between parasitic helminths and their hosts, p. 161-206. In D. Futuyma and M. Slatkin (eds.), Coevolution. Sinauer, Sunderland, MA.

HUBBELL, T. and R. NORTON. 1978. The systematics and biology of the cave crickets of the North American tribe Hadenoecini (Orthoptera: Saltatoria: Ensifera: Rhaphidophoridae: Dolichopodinae). Miscellaneous publications of the Museum of Zoology, University of Michigan, no. 156.

KANE, T. and G. BRUNNER. 1986. Geographic variation in the cave beetle Neaphaenops tellkampfi (Coleoptera: Carabidae). Psyche 93: 231-251.

KANE, T. and T. POULSON. 1976. Foraging by cave buetles: spatial and temporal heterogeneity of prey. Ecology 57: 793-800.

KANE, T., R. NORTON and T. POULSON. 1975. The ecology of a predaceous troglobitic beetle, Neaphaenops tellkampfii (Coleoptera: Carabidae: Trechinae). I. Seasonality of food input and early life history stages. International Journal of Speleology 7: 45-54.

KANE, T. and T. RYAN. 1983. Population ecology of carabid cave beetles. Oecologia 60: 46-55.

MARSH, T. 1969. Ecological and behavioral studies of the cave beetle Darlingtonea kentuckensis Valentine (Coleoptera: Carabidae). Ph. D. dissertation, University of Kentucky, Kentucky.

MITCHELL, W. 1968. Food and feeding habits of the troglobitic carabid cave beetle Rhadine subterranea. International Journal of Speleology 3: 249-270.

NORTON, R., T. KANE. and T. POULSON. 1975. The ecology of a predaceous troglobitic beetle, Neaphaenops tellkampfii (Coleoptera: Carabidae: Trechina). II. Adult seasonality, feeding, and recruitment. International Journal of Speleology 7: 55-64.

PECK, S. 1975. The life cycle of a Kentucky cave beetle, Ptomaphagus hirtus (Coleoptera: Leiodidae: Catopinae). International Journal of Speleology 7: 7-17.

SOKAL, R. and F. ROHLF. 1981. Biometry, 2nd ed. New York, N.Y. W. H. Freeman and Company.

WITTENBERGER, J. and R. TILSON. 1980. The evolution ot monogamy: hypotheses and evidence. Annual Review of Ecology and Systematics 11: 197-232. 